\title{
Tension Pneumocephalus after Frontal Sinus Fracture: Mount Fuji Sign
}

\author{
${ }^{1}$ Abhinav A Ranwaka, ${ }^{2}$ Arya S Mehta
}

\begin{abstract}
A 6-year-old child developed head injury and nasal bleeding and showed poor respiratory effort. The computed tomography scan of brain revealed frontal sinus fracture and pneumocephalus, which was causing mass effect on the frontal lobes leading to flattening of their convexity. There was widening of interhemispheric fissure with presence of air within. This mass effect on frontal lobes with separation of the frontal poles has been called "the Mount Fuji sign," and is suggestive of tension pneumocephalus.
\end{abstract}

Keywords: Frontal sinus fracture, Mount Fuji sign, Tension pneumocephalus.

How to cite this article: Ranwaka AA, Mehta AS. Tension Pneumocephalus after Frontal Sinus Fracture: Mount Fuji Sign. Int J Otorhinolaryngol Clin 2017;9(2):79-80.

\section{Source of support: Nil}

Conflict of interest: None

\section{CASE REPORT}

A 6-year-old female had a high-velocity vehicular accident followed by head injury and nasal bleeding. She fell unconscious and was brought to the trauma center. She showed poor respiratory effort and was intubated. A computed tomography scan of brain was performed (Fig. 1) which revealed fracture of the frontal sinus and air in the brain (pneumocephalus). This pneumocephalus was causing mass effect on the frontal lobes leading to flattening of their convexity. There was widening of interhemispheric fissure with presence of air within. In addition, there was pneumoventricle in lateral ventricles, third and fourth ventricle with cerebrospinal fluid (CSF) layering. Mild subdural and subarachnoid hemorrhage

\footnotetext{
${ }^{1}$ Senior Registrar, ${ }^{2}$ Registrar

${ }^{1}$ Department of Radiology, King Edward Memorial Hospital and Seth Gordhandas Sunderdas Medical College, Mumbai Maharashtra, India

${ }^{2}$ Department of Radiology, Kokilaben Dhirubhai Ambani Hospital, Mumbai, Maharashtra, India

Corresponding Author: Abhinav A Ranwaka, Senior Registrar Department of Radiology, King Edward Memorial Hospital and Seth Gordhandas Sunderdas Medical College, Mumbai Maharashtra, India, Phone: +919422032350, e-mail: abhinav. ichi@gmail.com
}

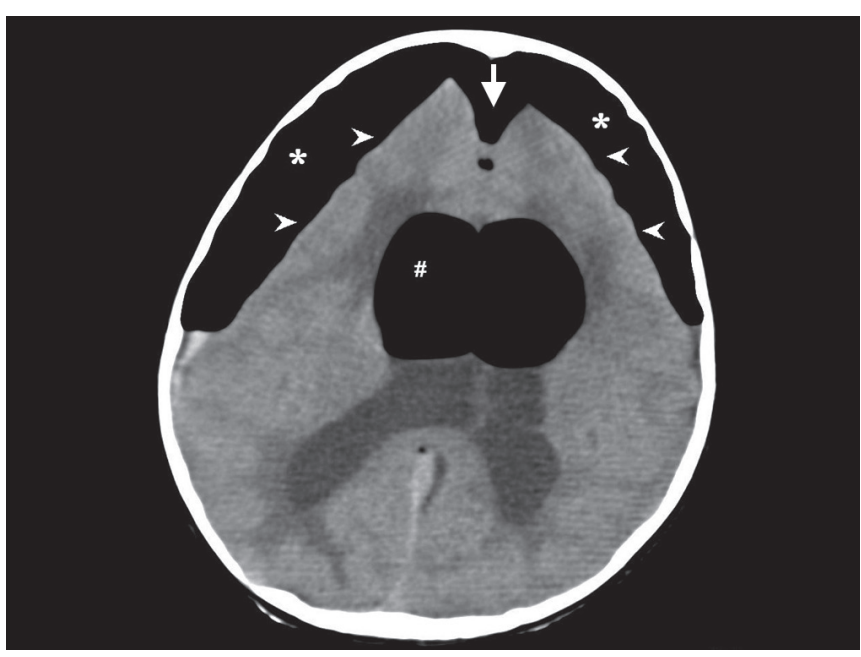

Fig. 1: Axial non-contrast CT scan of brain showing pneumocephalus $\left({ }^{*}\right)$ causing flattening of bilateral frontal lobe convexities (arrowheads) and widening of interhemispheric fissure with presence of air within (arrow), called as "Mount Fuji sign"; in addition there is pneumoventricle (\#).

was also present. Diagnosis of tension pneumocephalus was made. An emergency craniotomy was thereafter performed, which resulted in improvement of consciousness level and spontaneous respiration.

\section{DISCUSSION}

Pneumocephalus is not an uncommon phenomenon after fractures of the nose and paranasal sinuses. The mechanism of entry ${ }^{1,2}$ in such procedures can be explained by the "inverted bottle effect" where the CSF leak from the dural defect causes the air to get sucked into the subdural space, much like the phenomenon seen after inverting a filled bottle. In addition, after sneezing and coughing, excess air pressure forces the air into the calvarium, which may not be able to exit due to "ball valve effect" of the dural flap at the site of tear. When the pressure of this intracranial subdural gas rises (tension pneumocephalus), it causes mass effect on the brain, predominantly the frontal horns due to their nondependent location. If the pressure of this gas exceeds the surface tension of CSF (almost the same as water), it causes separation of the medial aspect of frontal lobe, which usually appears stuck together by CSF, and widening of the interhemispheric fissure. This mass effect on frontal lobes with 
separation of the frontal poles has been called "the Mount Fuji sign," after their resemblance to the famous volcanic mountain in Japan.

\section{CONCLUSION}

While mild pneumocephalus is harmless and usually resolves by itself, tension pneumocephalus can cause mass effect and deterioration of neurological status warranting urgent surgical intervention. The importance of urgent diagnosis and this sign, which can be picked up by junior residents, therefore, cannot be overemphasized.

\section{REFERENCES}

1. Komolafe EO, Faniran EA. Tension pneumocephalus-a rare but treatable cause of rapid neurological deterioration in traumatic brain injury. A case report. Afr J Neurol Sci 2010;29(2):88-91.

2. Thapa A, Agrawal D. Mount Fuji sign in tension pneumocephalus. Indian J Neurotrauma 2009;6(2):161-162. 